
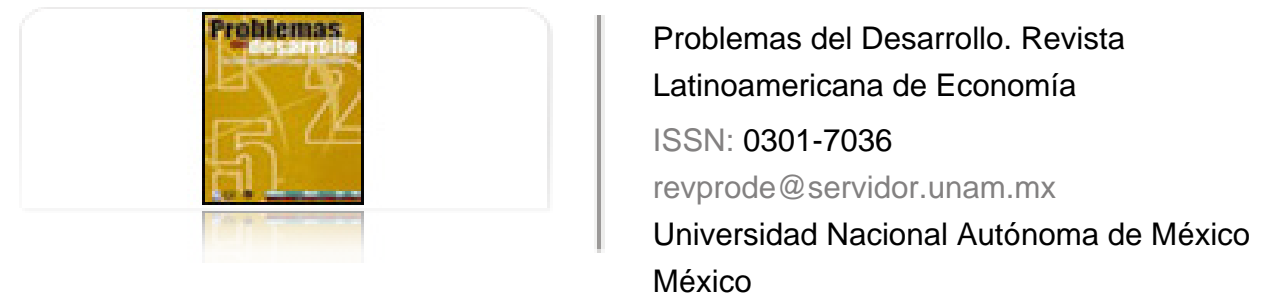

Vázquez Ruiz, Miguel Ángel

Grupos económicos en el norte de México

Problemas del Desarrollo. Revista Latinoamericana de Economía, vol. 35, núm. 137, 2004, pp. 95-115

Universidad Nacional Autónoma de México

Distrito Federal, México

Disponible en: http://www.redalyc.org/articulo.oa?id=11825947007

Cómo citar el artículo

- Número completo

- Más información del artículo

Página de la revista en redalyc.org

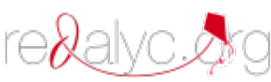

Sistema de Información Científica

Red de Revistas Científicas de América Latina, el Caribe, España y Portugal Proyecto académico sin fines de lucro, desarrollado bajo la iniciativa de acceso abierto 


\title{
Grupos eCONÓMICOS EN EL NORTE DE MÉXICO
}

\section{Miguel Ángel Vázquez Ruiz*}

Fecha de recepción: 5 de septiembre de 2002. Fecha de aceptación: 14 de junio de 2004 .

\section{Resumen}

Una de las contiendas más arduas en la región fronteriza entre México y Estados Unidos es librada en el campo de la economía. En función de ésta, los programas de zonas y perímetros libres, de industrialización vía maquiladoras y de artículos gancho, entre otros, son parte del trato de excepcionalidad dada a la zona por el Estado mexicano. Estos hechos han sido motivo de gran cantidad de estudios e investigaciones, particularmente los que tienen que ver con los obreros contratados para laborar en las maquiladoras. Empero, una variable importante en la formación, movimiento y crecimiento de la región fronteriza son los agentes empresariales involucrados en ese territorio. El objetivo del presente trabajo es analizar el origen, desarrollo y presencia competitiva de grupos económicos nativos líderes en la región, cuyo crecimiento tiene como fuente de sinergia el influjo de fuerzas tanto binacionales como globales.

Palabras clave: región fronteriza, empresarios nativos, grupos económicos, líderes, competencia globalizada, industria fronteriza.

\begin{abstract}
One of the hardest struggles along the Mexico-U.S. border region is taking place within the economic field. As a function of this, the free zone and perimeter programs, for industrialization via maquiladoras and give-away products, among others, are part of the exceptional treatment given to the zone by the Mexican State. These factors have led to many studies and much research, particularly with respect to the workers hired by maquiladoras. However, the business agents involved in that area are an important variable in the formation, movement and growth of the border zone. The aim of this study is to analyze the origin, development and competitive presence of leading local economic groups in the region, for whom the inflow of both binational and global forces develops as a source of synergy.
\end{abstract}

Key terms: border region, local business people, economic groups, leaders, globalized competition, border industry.

* Profesor-investigador del Departamento de Economía de la Universidad de Sonora. Correo electrónico: mvazquez@pitic.uson.mx 


\section{Résumé}

Une des batailles des plus ardues dans la région de la frontière entre le Mexique et les Etats Unis est celle qui est livrée dans le champ de l'économie. C'est en fonction de cette dernière, que les programmes des zones et des périmètres libres, d'industrialisation via les usines de sous-traitance et des articles appât, entre autres, sont l'objet d'un traitement exceptionnel de la part de l'Etat mexicain. Ces faits sont l'objet d'un grand nombre d'études et d'investigations, en particulier ceux qui ont une relation avec les ouvriers engagés pour travailler dans les usines de sous-traitance. Cependant, les agents patronaux involucrés dans ce territoire sont une variable importante dans la formation, le mouvement et la croissance de la région frontalière. L'objectif de ce travail est d'analyser l'origine, le développement et la présence concurrentielle des groupes économiques natifs leaders dans la région dont le développement a comme source de synergie l'influx des forces tantôt binationales, tantôt globales.

Mots clés: région frontalière, entrepreneurs natifs, groupes économiques, leaders, concurrence globalisée, industrie frontalière.

\section{Resumo}

Uma das mais árduas batalhas, que ocorrem na região fronteiriça entre o México e os Estados Unidos, está sendo travada no campo da economia. Em função desta contenda, os programas de zonas e perímetros livres, de industrialização via maquiladoras e de artigos ganchos, entre outros, sofrem um tratamento de excepcionalidade, conferido a esta área pelo Estado mexicano. Estes fatos têm motivado uma grande quantidade de pesquisas, particularmente os estudos relacionados aos operários contratados para trabalhar nas maquiladoras. Porém, é pouco discutida a participação dos agentes empresariais envolvidos nesse território, variável importante na formação, movimento e crescimento da região fronteiriça. $O$ objetivo do presente trabalho é analisar a origem, o desenvolvimento e a presença competitiva de grupos econômicos locais, líderes na região, cujo desenvolvimento tem como fonte de sinergia a influência de forças tanto binacionais como globais.

Palavras-chave: região fronteiriça, empresários nativos, grupos econômicos, líderes, competição globalizada, indústria fronteiriça. 


\section{Introducción}

$\mathrm{E}$

n el ámbito de las relaciones entre lo local y global, los espacios fronterizos son sui generis. Es el caso del norte de México, territorio donde se da una relación de interdependencia económica cuyo análisis deberá considerar variables como el origen de las regiones de uno y otro lado de la línea fronteriza, así como los vínculos de un itinerario que tiende a integrarlos en los niveles económico, social y cultural. En esa dinámica resulta clave el perfil de los agentes económicos involucrados, ya que la movilidad de una región suele darse, en gran parte, en función del tipo de empresario que en ella se haya desarrollado. En la zona, espacio de confrontación competitiva entre los agentes de un país poderoso, Estados Unidos, y de otro subdesarrollado, México, la mayoría de los agentes empresariales nativos no tiene la fuerza suficiente para enfrentar una competencia económica sumamente intensa entre empresas y grupos económicos. Sin embargo, hay excepciones en aquellos grupos que han tenido la capacidad de convertirse en líderes, marcando pautas para mantenerse con éxito en el mercado.

El objetivo del presente artículo es analizar los vínculos de una región con el perfil de empresarios nativos prevaleciente. Particularmente, se estudian los rasgos que definen a éstos, cuya templanza se ha manifestado en un espacio donde las coordenadas competitivas están determinadas por la convergencia de dos países con niveles de desarrollo económico distinto. Su condición de liderazgo deriva de su operación como grupo integrado vertical y horizontalmente, del monto de sus activos, sus ventas y de los empleos que generan.

Si bien el título del presente trabajo señala el norte de México como el espacio de estudio, conviene aclarar la ausencia de compañías de los estados de Baja California, Sonora y Nuevo León, especialmente Monterrey. Análisis previos de los dos primeros muestran que en ellos no existen grupos nativos que por su tamaño, integración y capacidad competitiva hayan alcanzado una posición de liderazgo a nivel nacional o internacional. En estas entidades, las grandes empresas trasnacionales subordinan a las nacionales y regionales. En el caso de Nuevo León, específicamente de Monterrey, ocurre todo lo contrario; en ese estado existen empresas nativas, muchas de ellas desde el siglo XIX, que son paradigmas de competitividad a nivel regional, nacional y global. Esta potencialidad hace de Nuevo León un estado profundamente distinto al resto de los fronterizos, de ahí que incluirlo como parte de la región norte sería una variable de distorsión de la homogeneidad de la historia económica . Asimismo, habría que añadir que la presencia geográfica de esa provincia en los límites fronterizos es insignificante, ya que sólo el municipio de Columbia tiene colindancia con Estados Unidos. 
El artículo se divide en varias partes. En la primera se aborda el tema de la conformación de la región norte de México, resaltando la importancia que en ese proceso han tenido los empresarios nativos. Una vez definido el espacio de estudio y sus agentes, en la segunda parte se describe a esos grupos, líderes en la región, prestándose atención a tres aspectos: origen, trayectoria e inserción en la nueva economía de la competencia globalizada. Estas compañías son: Chihuahua y Bermúdez, del estado de Chihuahua; Grupo Industrial Saltillo, de Coahuila y Grupo Argüelles, de Tamaulipas. Finalmente, se presentan las conclusiones obtenidas.

\section{Empresarios y región: un espacio con influencia binacional}

En la mayoría de los planteamientos tradicionales sobre desarrollo regional, el papel de los empresarios y sus distintas formas de organización — reales y formales — se ha considerado dato exógeno.

Es recientemente, en la década de los noventa, cuando el análisis de los empresarios aparece vinculado a los aspectos de territorio y región. Algunos autores los relacionan desde la perspectiva de la economía política, destacando básicamente los motivos de poder de las distintas fuerzas que operan en un territorio, entre las cuales destacan las empresariales. En ese sentido, un autor clásico del desarrollo regional en México dice: "lo más importante es situar a cada conjunto demográfico en el segmento que le corresponde, para siquiera aproximarnos a la noción de 'fuerza de poder', ya que éstas son las clases o grupos que realmente dirigen la marcha de una sociedad" (Bassols, 1999:268). Dentro de esas fuerzas, al autor le interesa, particularmente, el capital privado, tanto nacional como extranjero, y sus expresiones de concentración y constitución en oligarquías regionales (Bassols, 1999:271-294).

En un trabajo anterior sobre formación de regiones económicas, el propio Bassols (1993) incluyó el tema del gran capital privado y los grupos regionales, haciendo énfasis en los de Monterrey, Guadalajara y del noroeste. Esta visión coincide con planteamientos previos porque su punto de interés es la concentración, centralización y formación de oligarquías regionales. Empero, está ausente una interpretación acerca de la inserción cualitativa de los empresarios en ese entorno. En todo caso, las referencias empíricas que proporciona el autor son interesantes.

Uno de los autores que ha puesto a los empresarios en el centro de la escena regional es Carlos Alba, quien sostiene:

Los empresarios participan en forma notable en la conformación de ciertas regiones, aunque también éstas dan origen al surgimiento y consolidación de hombres de negocios con determinadas características. La identidad regional, frecuentemente promovida y cuidada por los empresarios, cobra importancia en la medida en que la actividad económica no pasa al plano nacional; cuando el mercado tiene singularidades que lo distinguen del nacional 
y cuando el peso de la administración federal no ahoga a la local. En este marco, la clase dominante regional, mediante el control de los recursos económicos, de la administración local y de la identidad regional, busca expandir su base material y promover sus propios intereses, haciendo compatibles [...] algunas de las principales instituciones de un área: familia, religión, política, empresa económica. Por tales motivos, las regiones son dinámicas, difíciles de definir, cambian con el tiempo (Alba, 1990:19).

En un trabajo colectivo de Carlos Alba, Ilan Bizberg y Hélène Rivière (1998) basado en varios estudios de caso en el nivel internacional, se arroja luz acerca de cómo las regiones y sus empresarios se suman a la globalización. Se analizan otros de reestructuración territorial y el papel de los empresarios locales. Más allá de lo económico, los autores describen lo que puede llamarse fortaleza regional, desigual según se trate de países desarrollados o economías emergentes. En efecto, respecto a los primeros sostienen que,

Las regiones que tienen mayor capacidad de acción sobre sí mismas se plantean el problema del desarrollo más allá del mero crecimiento económico, que incluye elementos sociales, culturales y políticos. Más aún, el dinamismo económico encuentra sustento en bases sociales y culturales porque aprovecha la sinergia de los agentes regionales y locales articulados a ciertos valores y creencias comunes, que se refieren al origen fundacional o a un futuro derivado de sus propios proyectos políticos regionales. Estas regiones están en condiciones de negociar con el Estado nacional su tipo de relación, exigir mayor autonomía y participación regional en la orientación de su propio desarrollo (Alba, et al., 1998:16-17).

En cambio, para países de menor desarrollo afirman que,

Las regiones con menor capacidad de acción, las que están ubicadas en las economías emergentes o en los países menos desarrollados, y peor aún, las más atrasadas, cuentan con estructuras económicas e instituciones sociales poco consolidadas. En ellas, la preminencia de algunos actores económicos y políticos se desarrolla en detrimento de otros agentes y de las comunidades locales; sus ventajas primordiales siguen siendo la venta de sus recursos a bajos precios (Ibid.:17).

Lo anterior es particularmente cierto en el caso de las región fronteriza de México con Estados Unidos, donde se presenta la gran paradoja de que siendo un territorio de importante peso económico, en general no cuenta con una clase empresarial nativa pujante que pueda frenar con éxito la expansión de capitales provenientes del extranjero e incluso de otras partes del país.

Una explicación de lo anterior se puede encontrar en las siguientes circunstancias: $a$ ) su proceso originario de acumulación de riqueza no es resultado de una cultura empresarial de hombres emprendedores, sino de haber establecido algún tipo de nexos con fuerzas de poder políticas de la época del porfirismo y posteriormente de la Revolución Mexicana; b) de lo anterior se deriva una relación histórica con el Estado mexicano, del que usufructuaron subsidios y precios de garantía en los mejores años de la expansión agrícola, que van de las décadas de los cuarenta a los sesenta; c) y aún más, muchos de esos 
empresarios participaron directamente en el poder público estatal y nacional desempeñando algún puesto, pasando de políticos a empresarios y viceversa (Vázquez, 1998:27-30).

En ese sentido, en una región fronteriza como la que conforman México y Estados Unidos, no existe correlación entre las exigencias competitivas propias de un espacio donde coinciden un país desarrollado y otro atrasado, y el tipo de actor económico presente en ese escenario. Las asimetrías económicas de los dos países se manifiestan en el perfil de los agentes económicos que operan en uno y otro país.

Sin embargo, lo anterior no corresponde a la imagen que los propios empresarios norteños tienen de sí mismos. Históricamente, ellos han cultivado un regionalismo que ante su propio espejo los hace ver como pioneros, innovadores, agresivos y competitivos. $\mathrm{Su}$ autoestima es muy grande, pero su quehacer mediano. Los empresarios de Sonora, por ejemplo, durante muchos años se autodefinieron como los agrotitanes que transformaron el desierto en vergel, lo que propició que hicieran de ese estado el granero de la república, honor que, por cierto, también se lo adjudicaron Tamaulipas y Guanajuato.

Posteriormente, cuando comenzaron a llegar maquiladoras que nada tenían que ver con el perfil productivo de la región — como parte de un proceso de dimensión internacional—, los empresarios de la frontera crearon un discurso que los hace ver como protagonistas de una dinámica que no controlan. La siguiente es una muestra:

Los empresarios de Chihuahua difunden con gusto la idea de que su creatividad y su sentido de la responsabilidad colectiva, guiada por los más ricos y prestigiosos, impulsaron los cambios económicos en la región fronteriza desde los años sesenta. Para propiciarlos, consideran que tuvieron que enfrentar una adversidad estructural nacional y regional: una adversidad política nacional y una adversidad geográfica regional (Rivière, 1998:34-35).

Ambas adversidades - en la cual una tiene que ver con los excesos de centralismo en la toma de decisiones para el apoyo a los estados y las regiones, y la otra, con problemas propios de un territorio semiárido: con poca disponibilidad del recurso agua, escasamente poblado, poco comunicado entre sí y alejado del centro del país — han influido para que la clase empresarial del norte de México haya fijado su meta económica en el mercado internacional, sobre todo en el sur de Estados Unidos.

Lo anterior ha propiciado que los empresarios norteños más representativos establezcan sus vínculos o redes más allá de la frontera, especialmente con los estados vecinos. Esto lo ha facilitado el hecho de que una gran parte de la población de origen mexicano —nativos inmigrantes - se concentra en los estados del sur, especialmente California y Texas.

En efecto, según Rivière:

Las diásporas constituyen hoy instrumentos particularmente reconocidos para la producción mundial de algunos empresarios locales. Es cierto, que ese fenómeno concierne particularmente a los asiáticos, pero se establecen también lazos con la inmigración mexi- 
cana en Estados Unidos, con las cámaras hispánicas de comercio y de industria, particularmente las de Texas y de California. Sin embargo, no se trata de relaciones tan estructuradas como las que unen a los miembros de la diáspora china, y sobre todo, el fenómeno no tiene la misma amplitud pero existe. En cambio, observamos la presencia de toda una serie de asociaciones locales, regionales e internacionales. Algunas tienen fines muy ligados a este elemento esencial de la identidad territorial que se distingue de la del centro, (Ciudad de México). Otras tienen como objetivo el reconocimiento de un prestigio de vasallaje entre poderosos y pequeños empresarios. Por último, existen adhesiones a networks cuyo origen suele encontrarse en Estados Unidos, y cuya meta es adquirir técnicas y conocimiento para una mayor competitividad. Es a menudo a través de estas redes que se construyen las distintas formas de contrato de cooperación entre empresas mexicanas y estadounidenses.

De acuerdo con los distintos tipos de redes, los sitios frecuentemente mencionados son del lado estadounidense: El Paso, Los Angeles, Alburquerque, Phoenix y Dallas; y del lado mexicano: Monterrey, Torreón, Monclova y la Ciudad de México (Riviére 1998:38-39).

A las redes anteriores, tendidas básicamente por actores privados, habría que añadir aquéllas donde los empresarios son llamados a participar en comisiones o proyectos formales al lado del gobierno en sus niveles municipal, estatal y federal. En ese sentido habría que mencionar los lazos entre los gobiernos estatales de las contrapartes mexicana y estadounidense. ${ }^{1}$

Finalmente, si bien el entorno general de la empresa está marcado por la globalización, su localización específica y los alcances de la realización de sus mercancías o servicios tiene siempre límites particulares que restringen o amplían su horizonte competitivo. De ahí que el vínculo concreto entre territorio y empresarios sea fundamental, no sólo para conocer una región, sino para dimensionar su capacidad de crecimiento y desarrollo. En ese sentido resultan esenciales su origen histórico y trayectoria; su manera de insertarse en la dinámica regional, nacional e internacional; su relación con el Estado y el gobierno estatal correspondiente; el campo económico de incursión; la temporalidad de los proyectos; la cultura empresarial que abarca riesgos; adaptación a la situación de la competencia; capacidad de innovación permanente; habilidad en el manejo de recursos financieros y disposición de ahorro; y visión de trascendencia más allá de la empresa personal o familiar para adoptar formas de organización capaces de enfrentar los retos de la competencia en cada modalidad de las etapas de la dinámica capitalista. En el caso particular del presente

1 Un ejemplo de lo anterior lo constituye Camino Real Economic Alliance (CREA), conformada por ciudades del corredor Camino Real: Las Vegas, Santa Fe, Alburquerque, Las Cruces, Nuevo México y El Paso, Texas; en el lado mexicano, las principales ciudades de la alianza son Ciudad Juárez y Chihuahua, capital del estado del mismo nombre

En el mismo sentido, la Comisión Sonora Arizona, en los últimos años (aproximadamente de 1991 a la fecha) ha buscado que sus encuentros vayan más allá de lo protocolario para constituirse en un organismo en el que además de los gobiernos participan otros actores, particularmente empresariales, buscando incorporase en algún tipo de negocio. En el marco anterior surgió la propuesta de impulsar un proyecto de gran visión estratégica Sonora Arizona, desde el cual se impulsan formas de integración a nivel sectorial entre ambos estados (Wong, 199:31 32). 
trabajo, cuyo espacio regional recibe gran influencia de Estados Unidos, específicamente de los estados del sur de ese país, se destaca la intensidad con que ocurre la internacionalización en una zona de sinergia bilateral.

\section{Empresas y grupos económicos nativos líderes en el norte de México}

Los estados que conforman la región norte de México han sido históricamente un espacio de disputa por el territorio y el establecimiento de límites a la nación, por la soberanía política y económica, y por la preservación de la identidad nacional. En esa confrontación han estado presentes fuerzas en conflicto, enmarcadas en el hecho circunstancial pero inalterable de que es el punto de encuentro entre dos países profundamente desiguales entre sí.

En tal contexto, y a partir de la redefinición territorial y económica que experimenta el país desde principios de la década de los ochenta, el norte de México es un espacio líder de la competencia mundial. Esas características implican que en esa región se muevan fuerzas económicas internacionales, nacionales, regionales y locales altamente desarrolladas. En este sentido, es especialmente importante analizarlas pues han conformado un mosaico, auténtico laboratorio de competitividad de inversiones estadunidenses, canadienses, asiáticas, europeas, latinoamericanas y también mexicanas. La cuestión es: qué tan poderosas son las fuerzas económicas nativas para confrontarse localmente con las corrientes de la economía global. Hasta ahora han sucedido dos cosas: muchos empresarios de la región tienden a desaparecer o a minimizar su poder económico e influencia política, y otros buscan prácticas nuevas para perpetuarse, como las alianzas estratégicas con capitales extranjeros. Esto ha implicado, en muchos casos, modificar las formas de organización, que han evolucionado del empresario individual al grupo familiar, y de éste a modalidades con asociaciones externas con otros individuos, familias e inclusive grupos. En algunos casos se ha llegado a la figura de la controladora, desde la cual el grupo opera teniendo como eje una empresa matriz que administra al resto de los negocios.

De esas empresas y grupos económicos, los que surgieron a partir de la política de privatizaciones del Estado mexicano han basado su estrategia competitiva en modernización tecnológica, introducción de formas flexibles de relación con sus trabajadores y modificación de esquemas administrativos. Tal es el caso de Grupo México y de Grupo Acerero del Norte, con Altos Hornos de México a la cabeza.

Los otros grupos, motivo central del presente trabajo, son las fuerzas económicas locales que han sobrevivido a la competencia globalizada. Éstos, aun cuando históricamente sustentaron parte de su éxito en la cercanía con el poder político del Estado, han visto limitada esa vía de competencia a partir de la concepción de Estado mínimo, y ahora ensayan nuevas fórmulas, como es la búsqueda de asociaciones con otros capitales que coadyuven a resolver problemas de financiamiento y mejoramiento tecnológico. En esta 
lógica se inscriben los grupos económicos líderes, nativos del norte de México: Chihuahua, Bermúdez, Grupo Industrial Saltillo y Argüelles.

A partir de la situación económica determinada por inversiones, ventas, empleos generados y modernización tecnológica, el mosaico de fuerzas económicas dominantes en esa parte del país se integra en orden jerárquico de la siguiente manera:

- Maquiladoras, predominantemente de capital extranjero (entre las más de 3000 que operan en el país destaca la productora de autopartes Delphi, de Estados Unidos, que cuenta con 57 plantas y un centro de tecnología distribuidos en veinte ciudades del país, donde ocupa 71500 personas, lo cual la coloca como la primera empresa privada en México por el número de empleos que genera); ${ }^{2}$ la industria automotriz que labora en los estados de Coahuila (General Motors y Chrysler) (Dávila Flores, 1998:43-45), Chihuahua (Ford ensambla motores) y Sonora (Ford ensambla automóviles). Estos son ejemplos de empresas extranjeras líderes en el norte de México, grandes consumadoras de la integración en la globalización, particularmente hacia Norteamérica. Asimismo, a partir de los noventa del siglo recién concluido, se han expandido hacia esta parte del país las grandes corporaciones internacionales de la minería estadounidense (Minera Hecla) y canadiense (Oro de Sotula, propiedad de Campbell Resources Inc., que aparece en la lista de las principales 25 inversiones de Canadá en México) (Vázquez Ruiz, 1997:17).

- Los grupos de punta del capital nacional, como CEMEX que opera en Baja California, Sonora y Coahuila; y Grupo Acerero del Norte, de gran presencia nacional (que en el norte se localiza en Coahuila y Sonora) a través de la empresa Baríta de Sonora; Grupo Industrial Bimbo, Grupo Gamesa, Cervecería Cuauhtémoc-Moctezuma y Sabritas, en Sonora.

- Los grupos nativos, que han logrado relacionarse con el capital internacional y nacional. Tal es el caso del Grupo Industrial Saltillo de Coahuila y de los llamados facilitadores de la integración como el Grupo Bermúdez y Chihuahua, en el estado del mismo nombre, y el Grupo FINSA- Argüelles de Tamaulipas; y Bachoco, nacido en Sonora y cuya base de operaciones se encuentra en Guanajuato.

- Después de los anteriores habría que colocar a los grupos locales que comienzan a desarrolar presencia internacional, entre los que destacan las frigoríficas sonorenses Alpro, Kowi y Valmo, exportadoras de carne de puerco a Asia.

Desde esta perspectiva, en que las grandes directrices de la economía norteña están marcadas, en general, por empresas externas, es importante conocer el perfil de los grupos

2 El Financiero, 26 de junio de 2002, p. 20. 
económicos nativos que compiten a partir de la plataforma que brinda la región. Ello requiere enlazar el análisis histórico con el presente, destacando las distintas estrategias y vínculos que los empresarios han adoptado en las diversas épocas para sobrevivir a las condiciones cambiantes de la competencia mundial. La condición para hablar de ellos es, como ya se mencionó, que sean empresarios nativos, constituidos en grupo económico ${ }^{3}$ y que desde su ámbito regional hayan diversificado sus actividades económicas y extendido su presencia hacia otras partes del país y el extranjero.

\section{Grupo Chihuahua}

La historia del estado de Chihuahua identifica dos nombres clave para explicar su origen y desarrollo económico, así como la conformación de la clase empresarial: la familia Terrazas y el Grupo Vallina. Por corresponder al objetivo del presente trabajo, el interés se finca en este último. ${ }^{4}$

La historia del Grupo Vallina se remonta a 1934, cuando un grupo de capitalistas que tenían como líder a Eloy Santiago Vallina García, crea el Banco Comercial Mexicano con un capital de $\$ 300000$.

Dice un estudioso del tema:

En él logró concitar empresarios e intereses de diversos orígenes: antiguos capitalistas regionales de origen porfiriano, con intereses en la ganadería, minería, el comercio, la industria o los bienes inmuebles; nuevos empresarios locales favorecidos por la revolución, entre los que se encuentran algunos militares; empresarios mexicanos o extranjeros radicados en la ciudad de México; estadounidenses interesados en aprovechar las oportunidades que se abrían en la región; profesionistas prestigiados del medio local. A partir de este banco se lograron establecer y consolidar relaciones económicas y sociales entre las principales familias de la élite económica chihuahuense. Nacieron así, desde los años treinta, muchos negocios comerciales, industriales y de servicios que al paso del tiempo formarían parte del llamado Grupo Chihuahua (Alba, 1998:205).

La empresa madre fue Celulosa de Chihuahua, fundada en 1952, la cual emitió acciones al público en 1956. En el directorio de la empresa, como controladores del capital social, han figurado José Antonio Vallina, Rafael Vallina Fernández y Eloy Vallina Laguera, como el ejecutivo principal (Camp, 1986:207).5

3 “El grupo es una empresa de muchas compañías que realiza transacciones en diferentes mercados pero bajo un control empresarial y financiero común. De manera más general, este modelo de organización industrial tiene dos aspectos esenciales. Primero, el grupo obtiene su capital y sus altos ejecutivos de fuentes que trascienden a una sola familia. Los administradores del capital pueden provenir de varias familias ricas, pero permanecen dentro del grupo como una sola unidad económica. Entre los propietarios administradores del grupo se encuentran de ordinario algunos ( pero no la totalidad) de los miembros de la familia en la que se origina la actividad del grupo" (Leff, 1978:663), citado por Camp (1986:196).

4 Sobre la presencia histórica de la familia Terrazas en Chihuahua consúltese el libro de Mark Wasserman (1988). 
Con el soporte financiero de un banco y una empresa productiva madre, más los hilos que habían tejido con el gobierno federal y otros empresarios del país, los Vallina llegaron a convertirse en el paradigma empresarial de Chihuahua, estatus que años atrás habían ocupado los Terrazas.

Como grupo empresarial, los Vallina desplegaron lo mejor de sí en el periodo conocido como sustitución de importaciones. A partir de la estabilidad financiera que alcanzaron con el banco, desarrollaron varias inversiones que dieron gran dinamismo al estado de Chihuahua, donde proliferó este grupo durante la década de los cuarenta. En 1941 iniciaron Cementos de Chihuahua, Papelera de Chihuahua y Avena de Chihuahua, S.A. Para 1945, Eloy Vallina y un grupo de capitalistas de Chihuahua compraron el Ferrocarril del Noroeste y las concesiones de los bosques aledaños. En 1947 adquirieron Fierro Comercial, S.A., de Ciudad Juárez (Eloy Vallina y David S. Russek). Para el año siguiente, el banco contaba con un capital de $\$ 12000000$ y, con la incorporación de las familias Trouyet, Aníbal de Iturbide y Galindo, crearon el Banco Capitalizador. En 1952, fundaron Celulosa de Chihuahua, que inició actividades en 1955; Aceros de Chihuahua, S.A., con participaciones del Banco Comercial Mexicano y capitales de las familias Márquez, Terrazas, Almeida, Guerrero, Cruz, Wisbrim y Castro. En 1956, el Grupo Chihuahua adquiere de Eriksson e IтT, —empresas de teléfonos - el sistema telefónico nacional, del cual posteriormente nació Teléfonos de México S.A. En 1960, Eloy S. Vallina murió y quedó al frente de las empresas su hijo, Eloy Vallina Laguera (Arroyo, 1996:43).

Según el mismo autor, para la década de los setenta el Grupo Chihuahua comenzó a desmembrarse. La unidad interna de éste grupo se vió minada cuando Eloy Vallina relegó a socios principales como Simón Gil, Rivero Mier, Castro, además a los Wisberun, Guerrero y Salas-Porras. Miembros importantes, como Oscar Almeida, Salvador Creel y Juan Muñoz, intentaron organizarse como grupo financiero, adquiriendo Crédito Mexicano y el Banco Longoria, empero, la nacionalización de la banca acabó por desgajar a ambos (Arroyo, 1996:52).

Iniciada la década de los ochenta, el Grupo Chihuahua recibió un doble golpe: por un lado, se decretó la mencionada nacionalización de la banca, y por otro, la apertura externa de la economía. Ambos sucesos ejercieron un impacto negativo en la estructura del grupo. Al nacionalizarse Multibanco Comermex, desapareció el eje de la red de empresas y al disminuir el proteccionismo de la economía, así como los apoyos del Estado, la actividad forestal resintió la competencia externa, lo que provocó la caída de labores de Ponderosa Industrial y el cierre momentáneo de Celulosa de Chihuahua. Estos hechos, que dividieron la holding, dieron lugar a la formación de nuevos grupos económicos en el estado de Chihuahua, como Argos — de la familia Fernández-, el consorcio Interceramic, de la

La historia de Eloy S. Vallina y particularmente de Celulosa de Chihuahua puede verse en Fuentes Mares (1968). 
familia Almeida - y el de Cementos de Chihuahua — de la familia Terrazas- - Un saldo más de todas estas transformaciones es que la familia Vallina Laguera se replegó a las actividades forestales, y posteriormente, incursionó como promotora de la industria maquiladora y realizó actividades financieras en el sur de Estados Unidos (Arroyo, 1996:70).

\section{Grupo Bermúdez}

A diferencia del Chihuahua - cuya trayectoria abarca gran parte de las etapas históricas de ese estado y del país, que es una especie de paradigma empresarial regional que sólo tiene parangón con los Terrazas - el Grupo Bermúdez es más reciente y su incursión en la economía estatal tiene un perfil más especializado.

Sus orígenes — se remiten a la década de los sesenta, cuando Antonio J. Bermúdez, quien tenía amistad con el presidente Adolfo López Mateos- fue nombrado director del Programa Nacional Fronterizo (PRONAF), puesto desde el cual se desempeñó como facilitador del gobierno y también como miembro de la iniciativa privada interesado en los negocios que como funcionario promovía. Desde esa posición, contribuyó a diseñar el Programa de Industrialización Fronteriza, el marco jurídico de la industria maquiladora de exportación, e inició la promoción privada y desarrollo de parques industriales que la instalación de plantas exigía (Salas-Porras, 1992:383).

El Grupo Bermúdez estuvo ligado originalmente a la industria de la construcción, el comercio y los servicios, llegando a controlar más de treinta empresas localizadas en distintos sectores. A partir de esas bases, su campo principal de acción es la promoción de la industria maquiladora de exportación. Sus principales inversiones están en el mercado de edificios industriales (20\%) y de terrenos para el mismo propósito (29\%); asimismo, vende terrenos urbanizados dentro y fuera de los parques industriales, edificios para instalación de maquiladoras y proporciona servicios como programas de albergue, subcontratación y coinversión. En la actualidad, las principales empresas del grupo son: Constructora Lobeira, Grupo Atisa, Grupo Argüelles y Parque Industrial Nogales. Cuenta también con una planta productora de bloques, una trituradora y una productora de asfalto (Arroyo, 1996:68).

El Grupo Bermúdez, según especialistas, "el facilitador de la industria maquiladora más fuerte a nivel nacional" (Salas Porras, 1992:385), comenzó un proceso de recomposición a principios de los ochenta, que básicamente consistió en la separación de ejecutivos para crear sus propios negocios. Es el caso de Federico Barrio Terrazas - hermano del ex gobernador del estado de Chihuahua, Francisco Barrio Terrazas-, quien también había trabajado con los Bermúdez, en la creación el Grupo Lintel, para dedicarse a "desarrolladores y constructores" (Arroyo 1996:69). 


\section{Grupo Industrial Saltillo}

Uno de los grupos nativos más representativos del norte de México es el Grupo Industrial Saltillo (GIS), del estado de Coahuila. Su origen se remonta a finales de la década de los veinte, cuando Isidro López Zertuche (1892-1959) fundó en Saltillo una pequeña empresa productora de artículos de metal llamada Isidro López y Hermanos (ILNOS). En ella se producían tubos y codos para estufas y calentadores, tinas y baños de lámina y artículos de aluminio. Integraban la empresa un empleado y cinco operarios. En 1932 se dió un paso en la consolidación de ILNOS al crearse el departamento de fundición que daría origen a la Compañía Industrial Fundidora del Norte, S.A. (CIFunsA) (Marroni, 1992:94). La fábrica creció y, para 1932, ILNOS se transformó en sociedad anónima tomando el nombre de Compañía Industrial del Norte, S.A. (CIFunsA). ${ }^{6}$

En los años cuarenta, inmerso en la industrialización nacional y la sustitución de importaciones, el Grupo Industrial Saltillo contaba ya con un número importante de empresas pequeñas. Pero fue hasta mediados de los cincuenta, cuando adquirió un perfil más definido, que intensificó su participación en los distintos sectores de la economía, estableció relaciones más directas con el capital financiero, diversificó y modernizó sus empresas y contrató mayor fuerza de trabajo. Estos cambios sentaron las bases para la conformación del grupo industrial conocido en la actualidad (Marroni, 1992:95).

En la década de los setenta, al calor de conflictos sindicales de las empresas CINSACIFUNSA, ${ }^{7}$ el grupo industrial emprende un proceso de modernización que consistió en la

reestructuración administrativa general y reorganización de la estructura del grupo; ampliación de las relaciones con capitales regiomontanos (HYLSA y ALFA); ejecución de un programa sistemático de inversiones para ampliar y modificar las plantas y crear otras, aumentando la capacidad y posibilidades de la producción, diversificando los productos; cierre de empresas poco rentables como Moto Islo, a pesar del proteccionismo gubernamental; diversificación de compradores relacionándose como proveedores de las grandes compañías extranjeras como GM, Chrysler, Ford, Volkswagen, Renault y Cummins; reestructuración y modernización tecnológica cambiando procesos, técnicas de producción y la organización de la misma; contratación de asesoría italiana para aumentar la calidad [...] aprovechamiento de todas las exenciones y facilidades otorgadas por el gobierno federal, particularmente los créditos preferenciales para la exportación, los Certificados de Promoción Fiscal (CEPROFIS), y, de manera muy especial la negociación de su deuda en dólares vía FICORCA, que les permitió enfrentar con ventaja las devaluaciones de los años ochenta (Cepeda, 1994:158-159).

Para los noventa, el GIS era uno de los pocos grupos regionales con presencia nacional e internacional. Como se puede observar en el Cuadro 1, el GIS opera con cuatro divisiones,

El Financiero, "Coahuila tierra de líderes", 1998, (suplemento especial).

7 Del 16 de abril al 3 de junio de 1974, 6 mil obreros llevaron a cabo una de las huelgas más importantes de que se tenga memoria en la región (Beltrán 1987:125). 
Cuadro 1

Estructura por divisiones y empresas del gIS

\begin{tabular}{lcll}
\hline $\begin{array}{l}\text { División artículos } \\
\text { para el hogar }\end{array}$ & $\begin{array}{c}\text { División metal- } \\
\text { mecánica }\end{array}$ & $\begin{array}{c}\text { División productos } \\
\text { para la construcción }\end{array}$ & $\begin{array}{c}\text { División } \\
\text { corporativa }\end{array}$ \\
\hline CINSA & CIFUNSA & Vitromex & Asgis \\
Santa Anita & Castech & Ceramérica & Centro Recreativo Isidro López \\
ENASA & DITEMSA & Cerámica San Luis & \\
ESVIMEX & Techmatec & St.Thomas Creations & \\
& & Éxito & \\
\hline
\end{tabular}

Fuente: hhtp://www.gis.com.mx y El Financiero, “Coahuila: tierra de líderes,” 1998 (suplemento especial).

tres de productos industriales y la cuarta de apoyo para el diseño y asesoría de sus empresas.

Según el presidente del consejo de administración del GIs, Isidro López del Bosque, la permanencia en el mercado se debe a concepciones como ésta:

Una economía globalizada requiere nuevas habilidades, competencia y actitudes del personal. Desarrollar una cultura de competitividad y conocimientos a todos los niveles de Negocios que conforman el Grupo Industrial Saltillo, ha sido y es un compromiso continuo. Nuestro personal es una ventaja competitiva que se traduce en creatividad e innovación, trabajo en equipo e integración en todo lo que se realiza. ${ }^{8}$

Específicamente resalta los factores siguientes:

Las extensas y ágiles redes de distribución, sus eficientes sistemas de producción, los esfuerzos de mercadotecnia que realizan, su claro potencial de crecimiento, el gran capital humano, la alta utilización de su capacidad y la cuidadosa administración, han sido los factores para que los negocios del GIS tengan la presencia que hoy mantienen a nivel mundial. ${ }^{9}$

Con el fin de impulsar "ventajas competitivas para sustituir importaciones", la producción del grupo se coloca en mercados muy diversificados. Por ejemplo: sus ventas de productos y servicios para la transportación de líquidos y gases representan $95 \%$ del consumo total del país; en el otro extremo se encuentra la producción de monoblocks y cabezas para motores automotrices, $90 \%$ de la cual se exporta a Estados Unidos y Canadá, e indirectamente a Europa, Asia y África. La participación en el mercado de Estados Unidos es de $14 \%$ y en el europeo de $4 \% .^{10}$

A diferencia de otras familias y grupos económicos del norte de México — que a partir de sectores como agricultura, comercio o servicios, han diversificado su quehacer hasta extenderse a todas las actividades del sistema económico-, el GIs ha sido y es preponderan-

$8 \quad$ Isidro López del Bosque, página web: www.gis.com.mx

$9 \quad$ Ibid.

10 GIS, página web: $w w w . g i s . c o m . m x$ 
temente un grupo de giro industrial. Como se puede observar en el Cuadro 2, quien originalmente se formó como grupo familiar, creció, incorporando como socios a grandes empresarios nacionales como Eugenio Clariond Reyes, del Grupo IMSA de Monterrey, y Claudio X. Gonzaléz, de Kimberly Clark de México.

Cuadro 2

Consejo de Administración del GIS

\begin{tabular}{ll}
\hline \multicolumn{1}{c}{ Nombre } & Puesto \\
\hline Isidro López del Bosque & Presidente \\
Javier López del Bosque & Vicepresidente \\
Joaquín Arispe de la Maza & Consejeros \\
Jorge Chapa Salazar & - \\
Julián Dávila Cepeda & - \\
Guillerm Elizondo López & - \\
Claudio X. González & - \\
Eduardo López Alanís & - \\
Armando López Recio & - \\
Antonio Madero Bracho & - \\
Andrés M. Sada Zambrano & - \\
Eugenio Clariond Reyes & - \\
Adán Elizondo Elizondo & Comisario \\
\hline
\end{tabular}

Fuente: página web: gis.com.mx/informe/info7.html

Otra de las prácticas del grupo ha sido la de comprar empresas que complementen sus cadenas productivas (es el caso de la adquisición de Acero Porcelanizado S.A. de C.V., - del Grupo Vitro de Monterrey, controlada por CINSA - que permitió a la división de artículos para el hogar consolidar su producción de artículos de acero esmaltado para cocina. Con este hecho, cinsA se convirtió en el fabricante más grande del continente americano es este ramo). ${ }^{11}$

Otro tipo de alianzas estratégicas son las establecidas con capitales internacionales. En su división metal-mecánica, CIFUNSA —empresa de fundición automotriz y conexiones para tubería - realizó una coinversión en la cual las partes participan cada una con 50\% con la empresa alemana VAW MOTOR GMBH, de la cual surgió la empresa filial Castech que fabrica blocks y cabezas de aluminio para motores automotrices.

Igualmente importante es la empresa del grupo llamada Techmatec, cuyo giro es el diseño y fabricación de maquinaria para la automatización de procesos industriales, mediante sociedad con la empresa italiana AMT Robotica. ${ }^{12}$

11 Gis, página web: www.gis.com.mx

12 Ibid. 
FINSA-Grupo Argüelles

Los orígenes del grupo Fraccionadora Industrial del Norte (FINSA-Grupo Argüelles) en Tamaulipas, remiten a los años del auge agrícola de Matamoros, que corresponden a la época de expansión y modernización de la agricultura mexicana en las décadas de los cuarenta y cincuenta. Sergio Argüelles Gutiérrez, cabeza del grupo familiar, fue durante años productor, comercializador y distribuidor de granos. Asimismo, se dedicó a la comercialización de maquinaria agrícola (Robles, 1998:58).

Los negocios de granos fueron el primer apalancamiento de la familia, que desde muy temprano reconoció la importancia de las asociaciones al realizarlas con Carretero Balboa - ex presidente municipal de Matamoros, agricultor y ganadero- y la familia Guerra (Robles, 1998:58).s

Una característica de Sergio Argüelles, según la misma autora, es su conciencia innovadora ya que sus empresas fueron de las primeras en crear semillas híbridas mexicanas, comprando las progenitoras a empresas privadas y universidades como la Texas A\&M y la Purdue. En la comercialización de maíz y sorgo alcanzaron una penetración de más de $50 \%$ del mercado nacional. Asimismo, destacaron en la producción de maíz palomero, llegando a satisfacer 100\% de la demanda nacional (Robles, 1998:58).

El gran salto de los Argüelles ocurrió con la industria maquiladora de exportación. Según la historia oficial de FINSA, desde su creación en 1977, emprendió un agresivo programa de promoción industrial, y ya para 1978 construyó en una superficie de 202 hectáreas su obra estratégica, el primer parque industrial en Matamoros. Los parques industriales desarrollan servicios de infraestructura, introducción de agua y tratamiento de desperdicios, espacios para proyectos de ingeniería, sistemas de seguridad, y desarrollo de proyectos habitacionales para gerentes y trabajadores.

Clave en la expansión de FINSA fue la audacia de Argüelles en su relación con General Motors, ya que cuando se supo que ésta planeaba instalarse en Matamoros:

Por medio de la subcontratación de un despacho de ingenieros, desarrollaron el primer plan maestro del parque industrial FINSA. Sergio Argüelles expuso los planes del parque en Detroit, cuando se presentó ante el presidente de General Motors para convencerlo de que se instalara en Matamoros y se ubicara específicamente en su parque. Una semana después, un comité de General Motors decidió realizar una visita a Matamoros para conocer los terrenos, aún cuando no estaban completamente urbanizados (Robles, 1998:60).

Según la misma autora:

La visita de este comité a la ciudad de Matamoros significó el inicio de una nueva etapa dentro de la trayectoria de FinsA, ya que General Motors no sólo representó el "punto de partida" en el desarrollo de servicios a las empresas maquiladoras por parte del Grupo Argüelles, sino que esta asociación con General Motors lo llevaría a expandirse posteriormente en México y el extranjero (Robles, 1998:60). 
El periodo de consolidación del grupo ocurre a mediados de los ochenta, en el marco de la apertura externa y los estímulos a la llegada del capital extranjero. A partir de entonces,

la firma despegó un conjunto de estrategias que se derivaron en el establecimiento de alianzas estratégicas, el diseño de conceptos innovadores, las redes establecidas con sus clientes y el desarrollo de servicios especializados. Los factores que estuvieron presentes en el crecimiento y expansión de FINSA, en el periodo que abarca de 1988-1994, definido a partir de que empieza su expansión en la frontera norte, con el desarrollo del parque en la ciudad de Nuevo Laredo, hasta finales de 1994, que representa un periodo de recesión dentro de la firma, causada por la crisis económica del país (Robles, 1998:65).

Su situación como empresa se fue complicando lógicamente, conforme daba el salto del ámbito regional al nacional — situación propia de los primeros años - hecho que comienza con la expansión a otros estados y municipios de la frontera norte hasta llegar a ciudades importantes del interior de la república.

A lo anterior hay que añadir la incursión del grupo en el mundo financiero. En octubre de 1993 emitieron bonos en la bolsa de Nueva York y, para diciembre de 1994, habían creado el Banco Alianza, cuyo capital se integró de la siguiente manera: capital estadunidense - entre los inversionistas destacaban el Texas Pacific Group - con 30\%; capital del Distrito Federal y Guadalajara, 20\% por entidad; y de Matamoros 25\%. El principal accionista y presidente del consejo de administración era Sergio Argüelles (Robles, 1998:101102).

Sin embargo, las actividades financieras no comenzaron en buen momento y las secuelas de la crisis de 1994 — fuga de capitales, inestabilidad del tipo de cambio, incremento de inflación y tasas de interés, así como la obvia caída en los ritmos de inversióndificultó al grupo el cumplimiento de sus compromisos financieros así como la venta de servicios de promoción. A mediados de 1996, tenía una deuda acumulada de 70 millones de dólares (Robles, 1998:104). Para hacer frente a su realidad financiera, vendió las acciones del Banco Alianza y buscó otras opciones de financiamiento, por ejemplo, alianzas estratégicas con sistemas de crédito no bancario, como la división financiera de General Electric. Con la premisa de cambiar para enfrentar la crisis, pasó del tradicional funcionamiento vertical a otro de subcontrataciones, en el cual la empresa opera básicamente en la parte de diseños y aspectos de ingeniería, y contrata el resto de los servicios con empresas especializadas (Robles, 1998:114).

Como se observa en el Cuadro 3, FINSA cuenta en la actualidad con 13 parques industriales distribuidos en la frontera noroeste y el interior del país.

Para ampliar su oferta, el grupo ha desarrollado FINSA's Nova, empresa en la modalidad de los programas Shelter, además de proporcionar los servicios tradicionales del parque industrial, ofrece al cliente otros como contratación de personal y asesorías fiscal y legal. 


\begin{tabular}{ll}
\multicolumn{2}{c}{ Cuadro 3 } \\
Distribucion de los parques industriales de FINSA \\
\hline $\begin{array}{c}\text { Ciudades en entidades } \\
\text { fronterizas }\end{array}$ & $\begin{array}{c}\text { Ciudades en entidades } \\
\text { del interior }\end{array}$ \\
\hline Matamoros/Brownsville & Querétaro \\
Nuevo Progreso/Laredo & Silao \\
Reynosa/McAllen & Zacatecas \\
Nuevo Laredo/Laredo & Cd. de México \\
Saltillo & Puebla \\
Monterrey & Los Mochis \\
Cd. Victoria & - \\
Tampico & - \\
Torreón & - \\
\hline
\end{tabular}

Fuente: FINSA-Grupo Arguelles, Industrial Parks, www.neosoft.com/FINSA/english/parks.html

En el contexto de la globalización, el grupo se promociona destacando los siguientes elementos:

a) Los lugares donde ofrecen sus servicios son propios para la "competencia global de las manufacturas".

b) Entre sus clientes más importantes sobresalen General Motors —uno de los primeros que contrató al grupo- y Volkswagen, en Puebla, que opera con el sistema de just in time.

c) Acorde con el interés de preservar el medio ambiente, cuenta con parques ecológicos. El de la ciudad de México, llamado "Parque de servicios tecnológicos", forma parte de un plan maestro sensible a los problemas del medio ambiente. ${ }^{13}$

\section{Conclusiones}

Uno de los espacios del mundo donde se presentan con mayor fuerza los procesos de integración productos de la globalización, es el que conforma la confluencia del sur de Estados Unidos con el norte de México. Indicadores de uno y otro lado muestran que allí se genera una fuente de energía económica y social como no hay otra en el mundo. ${ }^{14}$

La economía tiene una base diversificada. En el sur de Estados Unidos y el norte de México se practican todo tipo de actividades: agricultura, silvicultura, pesca, minería, agroindustrias, manufacturas, comercio y servicios.

Demográficamente, es un espacio de gran crecimiento al que llega la gente atraída por las oportunidades económicas y de empleo que se ofrecen. Y aun cuando esta región tiene un fuerte sustento en la economía primaria, muestra tendencia a la producción de manufacturas, comercio y prestación de servicios.

13 FINSA Grupo Argüelles, Industrial Parks, página web: www.neosoft.com/FINSA/english/parks.html

14 El tema lo hemos desarrollado en Miguel Ángel Vázquez (1997 y 1999). 
Una especificidad de la región que cada vez toma formas más diversas, son los distintos tipos de corredores económicos que la vinculan. Unos se han concentrado y otros son iniciativas formales que van avanzando. Los primeros tienen que ver con intercambios económicos manufactureros y comerciales, presentes a lo largo de la historia y que a partir de la apertura de los ochenta se han acentuado. Los segundos resumen la voluntad de gobiernos estatales de uno y otro lado de la frontera de formalizar regiones virtuales. ${ }^{15}$

Sin embargo, lejos de que los procesos fluyan de una subregión a otra en una dinámica de complementariedad — donde la parte atrasada tienda hacia la convergencia con la desarrollada — las asimetrías continúan y todo indica que en el largo plazo se acentuarán.

Si bien las regiones tienen siempre una base estructural de índole geográfica, económica e histórica, su dinámica está marcada por los ritmos sociales y políticos que marcan el Estado y los agentes económicos activos en ese territorio. En esa realidad subyace la calidad del empresario involucrado en la construcción de la región.

En general, destaca la fuerte presencia de empresas trasnacionales y otras que han llegado de distintos estados del país, como Nuevo León, Jalisco, Estado de México y Distrito Federal. En ese cúmulo de competencia empresarial, no todos los estados norteños considerados han logrado consolidar una clase empresarial que, por su organización y desempeño, sea capaz de sintonizarse con la competencia global. En Sonora, por ejemplo, empresarios surgidos a partir de los apoyos que el Estado mexicano otorgó a los cachorros de la revolución, lograron construir empresas de servicios y agrícolas de índole familiar, pero nunca se prepararon para dar el salto hacia la industria y formas de competencia más complejas. En ese sentido, Sonora carece de una clase empresarial con liderazgo.

En otros estados del norte existen empresas y grupos económicos que al interior de éstos se han convertido en paradigmas por imitar. Es el caso de los grupos Chihuahua, Bermúdez, Saltillo y FinsA-Argüelles, pese a que tienen perfiles distintos en sus giros de actividad, su presencia económica e influencia en el desarrollo de sus estados y del país es significativa.

Finalmente, si bien en la torre de Babel de la competencia global fronteriza, la industria maquiladora de exportación y la automotriz marcan pautas en procesos industriales manufactureros que generan empleo y divisas, la esperanza económica, social y de seguridad nacional depende en el largo plazo de lo que los empresarios locales y nacionales construyan en la región. De lo contrario, la desnacionalización del país será también territorial.

15 Al respecto puede consultarse Eduardo Zepeda y David Castro (1998:20 36); Pablo Wong González (1997:15 61) y Carmen Bocanegra Gastelum y Miguel Ángel Vázquez Ruiz (1997:1 13). 


\section{Bibliografía}

Alba Carlos, Ilán Bizberg, Hélène Rivière, (compiladores), Las regiones ante la globalización, México, CEMCA, orstom, El Colegio de México, (introducción), 1998.

Alba Vega, Carlos, "Tres regiones de México ante la globalización: los casos de Chihuahua, Nuevo León y Jalisco", en Carlos Alba, Ilán Bizberg, Hélene Rivièré (compiladores), Las regiones ante la globalización, México, CEMCA, ORSTOM, El Colegio de México, 1998.

_ "Las regiones industriales y los empresarios de México", Revista Mexicana de Sociología, Instituto de Ciencias Sociales de la UNAM, año LII/núm. 2, abril/junio, 1990.

Arroyo Galván, Manuel, Chihuahua 1980-1995: grupos económicos y proyecto regional de desarrollo, tesis para obtener el grado de Maestro en Desarrollo Regional, Tijuana, El Colegio de la Frontera, septiembre, 1996.

Bassols Batalla, Ángel, “ Las fuerzas del poder: un bosquejo inicial", en Ángel Bassols Batalla (coordinador) y Javier Delgadillo (compilador), La Gran Frontera. Franjas fronterizas MéxicoEstados Unidos, transformaciones y problemas de ayer y hoy, México, Instituto de Investigaciones Económicas, UNAM, 1999.

- México: formación de regiones económicas, México, Instituto de Investigaciones Económicas, UNAM, 1993.

Beltrán, Rosa Esther, "Los principales conflictos y el uso de las leyes (1974-1986)", en Mario Dávila (coordinador), La economía, la política y los movimientos sociales en Coahuila, Departamento de Investigaciones Económicas, Universidad Autónoma de Coahuila, 1987.

Bocanegra Gastelum Carmen y Miguel Ángel Vázquez Ruiz, "Nuevas Formas de Integración de las regiones con la globalidad", en Notas, INEGI, 1997.

Camp A., Roderic, Los empresarios y la política en México, México, Fondo de Cultura Económica, 1986.

Cortina Ortega, Gonzalo, Prontuario Bursátil y Financiero, México, Trillas, p. 87.

Dávila Flores, Mario, Análisis del sector exportador de Coahuila, Saltillo, Coordinación General de Estudios de Posgrado e Investigación, Universidad Autónoma de Coahuila, 1998.

Cepeda Flores, Francisco, "Coahuila", en Pablo González Casanova y Jorge Cadena Roa (coordinadores), La República Mexicana. Modernización y democracia de Aguascalientes a Zacatecas, México, La Jornada Ediciones y Centro de Inves- tigaciones Interdisciplinarias en Humanidades de la UNAM, 1994.

El Financiero, “Coahuila: tierra de Líderes”, 1998. (suplemento especial).

FINSA:Www.neosoft.com/FINSA/english/parks.html Fuentes Mares, José, Eloy S. Vallina, México, Jus, 1968.

GIS: WWW. GIS.com.mx/informe/info $7 . h t m l$

Leff Nathaniel, "Industrial Organization and Entrepreneurship in the Developing Countries: The Economic Groups", en Economic Development and Cultural Change, vol. 26, julio, pp. 661-675, 1978; citado por Rodoric A. Camp, Los empresarios y la política en México, México, Fondo de Cultura Económica, 1986.

Hoshino, Taeko, "La expansión de los grupos industriales bajo el auge petrolero y el ajuste ante la crisis", en Pedro López Díaz (editor), México: La élite empresarial, Seminario : Economía, Estado y Sociedad : La macrofísica del poder en México, digesto de lecturas, vol. 1, Facultad de Economía, División de Estudios de Postgrado, Programa de Doctorado, unAm, 1996.

Marroni de Velázquez, Gloria, Los orígenes de la sociedad industrial en Coahuila 1840-1940, Saltillo, Archivo Municipal de Saltillo, 1992.

Rivière Hélène, "Elaboración de una nueva configuración regional, simbólica y real por parte de los empresarios locales del norte de México", en Carlos Alba et al., (coordinadores), Las regiones ante la globalización, México, CEMCA, orstom, El Colegio de México, 1998.

Robles González, Claudia María, Los promotores industriales en Matamoros. El caso de FINSAGrupo Argüelles, tesis para obtener el grado de Maestro en Desarrollo Regional, Tijuana, El Colegio de la Frontera, septiembre, 1998.

Salas-Porras, Alejandra, "Estructuras, agentes y constelaciones corporativas en México durante la década de los noventa", Revista Mexicana de Sociología, Instituto de Investigaciones Sociales de la UNAM, año LIX/núm. 4, octubre-diciembre, 1997.

, "Los facilitadores de la integración", en Benito Rey Romay (coordinador), La integración comercial de México a Estados Unidos y Canadá ¿Alternativa o destino ?, México, Siglo XXI-IIECUNAM, 1992.

Vázquez Ruiz, Miguel Ángel, Fronteras y globalización. Integración del Noroeste de México y el Suroeste de Estados Unidos, México, IIEC-UNAM, 1997a. 
- "La presencia canadiense en Sonora", Revista Universidad, nueva época, núm. 8, Universidad de Sonora, abril, 1997b.

, "Región e integración fronteriza MéxicoEstados Unidos”, Región y Sociedad 17, El Colegio de Sonora, enero-junio de 1999.

Waseerman, Mark, Capitalistas, caciques y revolución. La familia Terazas de Chihuahua, 1854-1911, México, Grijalbo, 1998.

Wong González, Pablo, "Integración de América del norte. Implicaciones para la competencia internacional de regiones", en Guillermo Ibarra
Escobar (compilador), Relaciones México California, más allá de la frontera, Culiacán, Universidad Autónoma de Sinaloa/ Sistema de Investigación del Mar de Cortés, 1997.

Zepeda, Eduardo y David Castro, "Manufactura y servicios en el norte de México", El Mercado de Valores 3/98, Nacional Financiera, marzo, 1998. 